ZOOLOGIA 30 (6): 607-614, December, 2013

http://dx.doi.org/10.1590/S1984-46702013005000014

\title{
Factors influencing the selection of communal roost sites by the Black Vulture Coragyps atratus (Aves: Cathartidae) in an urban area in Central Amazon
}

\author{
Weber G. Novaes ${ }^{1,3} \&$ Renato Cintra ${ }^{2}$
}

\author{
1 Programa de Pós-graduação em Ecologia, Instituto Nacional de Pesquisas da Amazônia. Caixa Postal 2223, \\ 69080-971 Manaus, AM, Brazil. \\ ${ }^{2}$ Coordenação de Biodiversidade, Instituto Nacional de Pesquisas da Amazônia. Caixa Postal 2223, 69080-971 Manaus, \\ AM, Brazil. \\ ${ }^{3}$ Corresponding author. E-mail: webernovaes@gmail.com
}

\begin{abstract}
Increasing populations of the Black Vulture, Coragyps atratus (Bechstein, 1793) and the capacity this bird has to live near humans has resulted in vulture-human conflicts. These conflicts increase the need for the effective management of vultures. Improved understanding of communal roosting dynamics is a key aspect of vulture biology that provides information for effective management that can mitigate conflicts. Here we investigated factors influencing roosting site selection by Black Vultures in Manaus. We monitored 40 native vegetation remnants (VR), visiting each VR twice (two independent observers) between 5:00 p.m. and 6:00 p.m. once every two-three months from June to November 2011. Using maximum-likelihood analysis and information-theoretic multimodel inference, we investigated the effects of VR covariates (size, shape, and location relative to feeding sites, to thermal power plants, and to other VRs) on VR occupancy by roosting Black Vultures. Distance to feeding sites (mainly garbage-dumping sites) was identified as the most important covariate (model-averaged $\beta=-0.62, S E=0.26$ ) and the other variables had no significant effects. Our results indicate that Black Vultures adjusted to the nearest possible roost to the food source to reduce the cost of movement. This suggests that reducing Black Vulture access to food through simple waste management and sanitation policies, including public education, may help reduce vulture-human conflicts in Manaus.
\end{abstract}

KEY WORDS. Aircraft; bird strikes; vulture-human conflicts.

Black Vultures, Coragyps atratus (Bechstein, 1793), are common in urban environments, and their populations have grown significantly in recent years (BUCKLEY 1999, Avery 2004), increasing the numbers of conflicts with humans. Examples are nuisance roosts, property damage, livestock depredations, and collisions with aircrafts (Lowney 1999, Avery \& Cummings 2004, Blackwell \& Wright 2006). In the United States alone, air strikes with Black Vultures cost over US\$ 25 million to the US Air Force (USAF 2009). From the perspective of the aviation industry, aircraft strikes are considered the main problem caused by vultures in Brazil. The Aeronautical Accidents Investigation and Prevention Center (CENIPA) recorded more than 980 strikes involving vultures between 2000 and 2011. In Manaus, a total of 65 vulture-aircraft strikes were recorded from 2000 to 2012 (CENIPA 2012).

These problems illustrate the increasing need for an effective management of vulture populations in order to reduce vulture-human conflicts. This requires a sound understanding of key aspects of the biology and behavior of Black Vultures. Communal roosting (defined as the "aggregation of more than two birds that sleep together"; Beauchamp 1999: 677) is one such key aspect. This strategy is thought to bestow benefits in terms of reduced thermoregulation costs, reduced predation risk, and/or increase foraging efficiency (WARD \& ZAHAVI 1973, Eiserer 1984, Hatchwell et al. 2009).

Among the main benefits attributed to communal roosting are opportunities for social interaction, information exchange, and facilitation of group foraging (RABENOLD 1986, 1987, Buckley 1996, 1997). Communal roosts are complex and comprise a series of spatially closed roosts used by a local population of vultures that alternates among such roosts in a given area, forming a roosting system (STOLEN \& TAYLOR 2003). These complex communal roosts have been the subject of several studies that address habitat characteristics, social behavior, movements between roosts, seasonal and daily use patterns, and population dynamics (RABENOLD 1986, 1987, Wright et al. 1986, Thompson et al. 1990, Buckley 1998, Stolen \& Taylor 2003, Evans \& Sordahl 2009, McVey et al. 2008, LambertucCi et al. 2008). However, one key question remains poorly investigated: what drives the selection of communal roosting sites by urban Black Vultures at the landscape scale?

In this study, we investigated the effects of the covariates of five vegetation remnants (VR) on VR occupancy by roosting Black Vultures. Two VR covariates were related to size and shape, 
and three were related to VR locations: distance to feeding sites; distance to thermal power plants; and distance to the nearest VR. Black Vultures normally use roosts in protected areas where human activities are limited and from which they can easily take off or land (COLEMAN \& Fraser 1989, Thompson et al. 1990). We hypothesized that the larger and more round VRs harbors sites that are more isolated and protected from of human activities, which facilitates arrivals and departures of Black Vultures. As Black Vultures can form communal roosts near predictable food sources (COLEMAN \& FraSER 1989), we expected that VRs near areas with larger amounts of organic residues would increase the probability of finding vulture roosts. Roosts are also often located near structures that generate upward-flowing air that facilitates early-morning flights (Thомpson et al. 1990). In Manaus, thermal power plants attracted vultures to their vent pipes (vultures use the mass of expelled heat as an aid to soar and fly) (Novaes, unpublished data). Similar behavior was observed in Turkey Vultures (MANDEL \& Bildstain 2007), which suggests that the proximity to thermal power plants might be favorable for the establishment of a communal roost. As Black Vultures form a complex of communal roosts comprised of a series of nearby roosts (RABENOLD 1987), the proximity to other VRs (potential ancillary roosts) may influence the probability that a VR is used to roost.

Manaus is a good study site to investigate the selection of communal roost sites by the Black Vulture. This unplanned and fast growing city has experienced increased environmental disturbances such as deforestation, water pollution, and shortage of basic sanitation in the last decades. Black Vulture populations have likely benefited from the foraging opportunities that have been enhanced by the large amounts of available organic residues. Moreover, there are several native vegetation remnants (mainly forest fragments) that are potential communal roost sites for Black Vultures. Furthermore, there are three airports in the urban area of Manaus: the Eduardo Gomes International Airport, the Ponta Pelada Air Base, and the Flores Aerodrome. The establishment of a vulture communal roost close to one of these aerodromes poses a serious risk to aviation. Our objectives were to investigate how structural features and the spatial location of VRs contribute to the probability that a VR will be used as a Black Vulture communal roost. Based on the results, we propose management actions to keep vultures away from airports.

\section{MATERIAL AND METHODS}

Manaus $\left(03^{\circ} 08^{\prime} \mathrm{S}, 60^{\circ} 01^{\prime} \mathrm{W}\right)$ is one of the main cities in the Brazilian Amazon. It has an urban area of 3,77.4 km² surrounded by the Amazon Forest, and about 1.8 million inhabitants. The climate is tropical, warm and humid, with a local rainy season between December and May and a dry season from June to November.
Several types of roosting substrates, such as trees, cell towers or tall buildings can be used as a roost by vultures. However, in our study area, vulture roosts in sites other than VRs are rare, probably due to the large availability of VRs. Therefore, our study included only VRs. Our sampling consisted of multiple visits to VRs of different sizes, shapes, and locations (Fig. 1). All VRs present in the urban area of Manaus that ranged from small tree aggregations ( $<1 \mathrm{ha}$ ) to a large forest fragment (>500 ha) were identified. We identified 197 VRs and to each VR we assigned a number in ascending order from North to South. The function sample (replace $=$ false) in the R software was used to randomly select 40 VRs. The number of observation points within each VR varied according to size, as follows: < 10 ha $(\mathrm{N}=21)$, one observation point per $\mathrm{VR}$; $10-150$ ha $(\mathrm{N}=15)$, two points; $151-300$ ha $(\mathrm{N}=2)$, three points, and $>300$ ha $(\mathrm{N}=2)$, four observation points per VR.

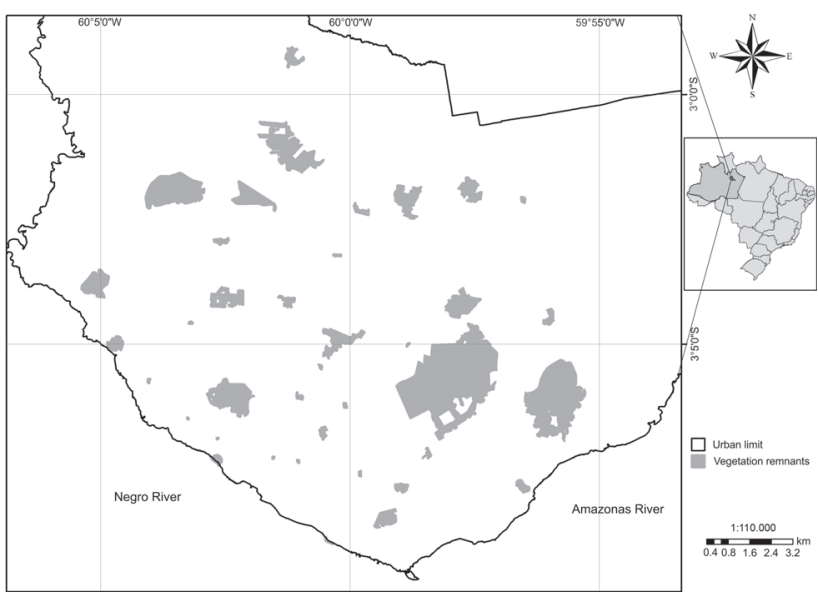

Figure 1. Spatial distribution map of the 40 vegetation remnants investigated for occupancy by communal roost of Black Vultures (Coragyps atratus) in the urban area of Manaus, Amazonas, Brazil.

We monitored five communal roosts of Black Vultures before establishing the time and length of the observations at each observation point. These sites are characterized by large numbers of individuals (RABENold 1986, Wright et al. 1986, BUCKLEY 1998). Given that our previous observations had identified that vultures arrive continuously in communal roosts in the later afternoon, we established $10 \mathrm{~min}$ observations periods at sunset (between 5:00 p.m. and 6:00 p.m.).

Observations were carried out at the edges of the VRs, which were usually on the streets bordering these areas. VRs were considered occupied if, from at least one observation point during each observation period, we observed vultures roosting and/or arriving in it. Larger VRs, i.e. with two, three or four observation points, were considered occupied if vultures were observed roosting in only one or more points. 
Our sampling design was based on estimating the proportion of sites occupied by a species of interest, as proposed by MacKenzie et al. (2002). Following this approach, the site occupancy status does not change for the duration of the survey period, no new sites are occupied after the survey begins, and no sites are abandoned before the survey ends. Species are never falsely detected at a site when they are absent, and a species may or may not be detected at a site when it is present. We surveyed the VRs within a short period of time (four months and a half) assuming that the VR occupancy did not change during our survey period. Based on MacKenzie \& Royle (2005) and considering the high detection probability ( $>0.9$ ) of vultures in the communal roost sites chosen, our sampling consisted of two observers simultaneously visiting VR observation points twice between 16 June and 1 November 2011. Observers positioned themselves at least $30 \mathrm{~m}$ from each other. Altogether, there were three trained observers conducting observations during this study. Due to logistical constraints, some VRs were not surveyed during all sampling occasions. These missing observations were accommodated using the proposed likelihood model (MACKenzIE et al. 2002).

We measured VR sizes using images from Google Earth (images from 2 August 2010) and the GEPath 1.4.6 software (SGRILLO 2012). To estimate VR shapes or deviation from a circle (a circular VR assuming an shape index, SI $=1.0$, and all other shapes assuming higher values), the Patton shape index (SI) (PATTon 1975) below was used: $\mathrm{SI}=\mathrm{P} \times(\pi \times \mathrm{A})^{0.5} / 200$, where $\mathrm{SI}=\mathrm{VR}$ shape index, $\mathrm{P}=$ perimeter of the $\mathrm{VR}$ in $\mathrm{km}, \pi=3.1416, \mathrm{~A}=\mathrm{VR}$ area in $\mathrm{km}^{2}$.

To estimate distance to food source, we identified vulture feeding sites using sampling points across urban and suburban areas of Manaus between 2009 and 2010. The sampling consisted of four visits to 48 sites between July and October 2009 and five visits to 80 sites between September and November 2010. The addition of 32 more sites in 2010 allowed us to increase the study area and include structures such as street markets, dumps, and polluted streams in the sample. At each site, vulture sampling lasted five minutes and was conducted by a single observer between 8:00 a.m. and 5:00 p.m. We considered feeding sites as those where Black Vultures were observed foraging for at least $80 \%$ of the observations. To investigate the use of thermal power plants by vultures, we monitored six of the 11 thermal power plants in the urban area of Manaus from February to September 2012. We observed that all thermal power plants were used by vultures and were visited more often in the early morning and/or late afternoon. To estimate the distance to other VRs, we considered the distance from the sampled VR to the nearest VR in the urban area of Manaus. Distances to the nearest VR, to the feeding sites and to thermal power plants were measured using Google Earth 6.1.

Our data analysis consisted of two steps. Firstly, we used descriptive analysis to assess the number of VRs occupied, their size and shape, variations in the distance of occupied VRs to feeding sites, thermal sources and other VRs. Secondly, we used a procedure of parameter estimation and multimodel inference (Burnham \& Anderson 2002). Each model tested has two components: one to estimate the probability that a VR would be occupied by Black Vultures $(\Psi)$ (a biologic component) and another to express the probability that we would detect Black Vultures in a VR where they actually occur (p) (a sample component). Both components can incorporate covariates, where it is possible to evaluate the effect of the covariates on psi and p.

We inputted a complete set of additive logistic regression model for the five variables, estimating the weighted mean effect sizes, and the relative importance of each variable based on the set of models. Using the PRESENCE software (HINES 2006), we built models that provided the maximum-likelihood estimates of parameters and their standard errors (SE). The models were compared using Akaike's Information Criterion corrected for small sample sizes (AICc). The AIC is a theoretic information measure used to select a parsimonious model that considers data variation and the number of parameters (Burnham \& ANderson 2002). The relative importance of each variable (w) was estimated, within model set, as the sum of Akaike weights over all models in which the variable was present; the $w_{\max }=1$ and variables with $\mathrm{w} \leqslant 0.35$ were considered unimportant. The weighted mean effect size $(\beta)$ was estimated for each variable in the model set as the sum of model-specific effect sizes times model-specific Akaike weights. The model set included a null model representing the hypothesis that none of the variables influenced the probability of Black Vultures occupying VRs as communal roosts. We were also interested in measuring the effect of observers and VR size with the probability of roost detection, for doing so we tested models with these variables as detections covariates.

\section{RESULTS}

Each observation point was visited 3.34 times on average (range 2-4 times). Overall, we detected the Black Vultures roosting in 17 of the 40 VRs sampled (42.5\%). Among 17 roosts identified, $14(82 \%)$ were less than $2 \mathrm{~km}$ from feeding sites, 9 (53\%) were less than $1 \mathrm{~km}$, and 7 (41\%) were less than $0.5 \mathrm{~km}$. Only 3 (17\%) were farther than $2 \mathrm{~km}$ from feeding sites (Fig. 2, see also Appendix 1). In other words, the closer a VR was to sites with available food, the greater the chance the VR was used as a communal roost (an increase of $1 \%$ per meter, see Fig. 3). We observed vultures roosting in VRs of different sizes, from very small ( $0.31 \mathrm{ha})$ to large forest fragments (773 ha) (Appendix 1). Similarly, Black Vultures used both rounded and irregularly shaped VRs (Appendix 1). The use of VRs seems not to be influenced by either distance to other VRs or to thermal power plants, since both VRs close or far from other VR and thermal power plants had vultures roosting (Appendix 1).

As expected, the null model did not provide an adequate explanation of the data (Appendix 2). The effect of the observer (Observer $1=0.97$, Observer $2=0.96$, and Observer $3=0.97$ ) 


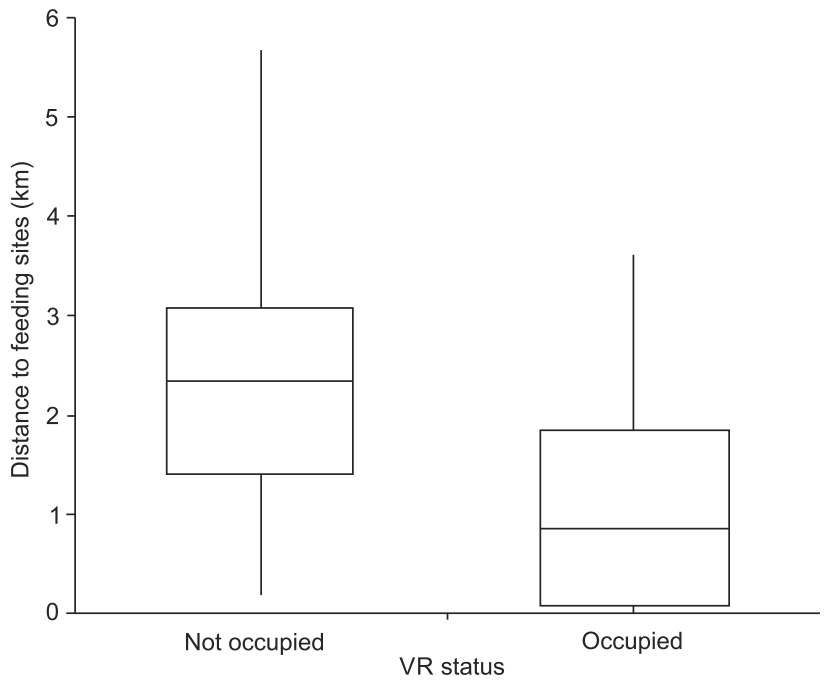

Figure 2. Box plot with median and quartiles feeding site distances from vegetations remnants that are occupied and unoccupied by Black Vultures as communal roosts, Manaus, Amazonas, Brazil.

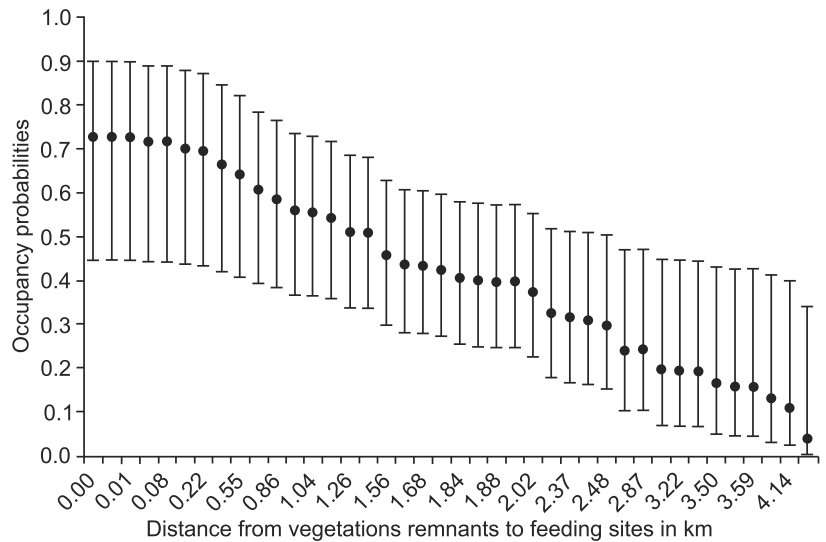

Figure 3. Estimate of occupancy probability of vegetation remnants as communal roosts of Black Vultures (Coragyps atratus) for each covariate, with error bars showing $95 \%$ confidence bounds.

and of the VR size (varied from 0.96 to 0.97 ) showed no significant variations on detection probabilities. Therefore, we considered the detection probability as constant in our model set. The occupancy estimates for each VR by Black Vultures was 0.42 $\left(\mathrm{SE}=0.07 ; \mathrm{CI}_{95 \%}\right.$ 0.28-0.58) and the probability of detecting Black Vultures in the VRs in which they occurred was 0.97 ( $\mathrm{SE}=0.02$; $\mathrm{CI}_{95 \%}$ 0.88-0.99).

Our model set comprised 32 models with all possible combinations of the variables and one null model (Appendix 2). The best-performed models ( $\Delta$ AIC $\leqslant 2$ ) are provided in Table I. In terms of relative importance, the variables rank as follows: distance to feeding sites, $\mathrm{w}=0.91$; distance to thermal power plants, $\mathrm{w}=0.35$; shape of $\mathrm{VR}, \mathrm{w}=0.30$; size of $\mathrm{VR}, \mathrm{w}=0.26$; and distance to other VRs, $\mathrm{w}=0.23$. The distance between VRs and the nearest feeding site was the most important predictor of VR occupancy by roosting Black Vultures, with a strong negative effect on occupancy ( $\beta=-0.62)$; although the precision of this estimate is somewhat low ( $\mathrm{SE}=0.26)$, it is significantly different from zero at $\alpha=0.05$ (95\% CI -1.13, -0.11; see Fig. 4). The other variables had either little or no significant effect on VR use by Black Vultures as communal roost (Fig. 4).

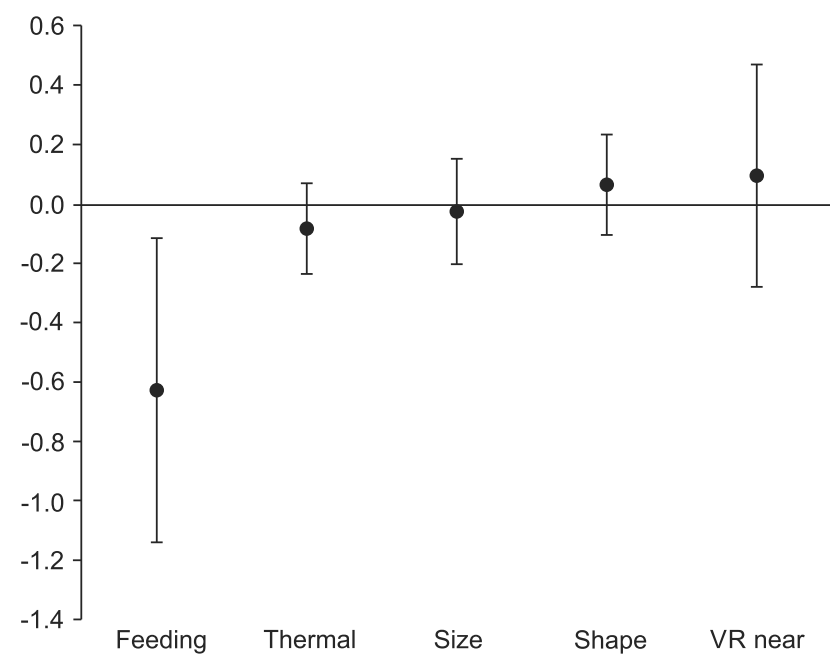

Figure 4. Model-averaged effect-size ( $\beta$ coefficients) of variables from the 32-model set. Error bars show $95 \%$ confidence limits, where they do not intersect the dotted line, we consider the effect of the variables on vegetation remnant occupancy to be significant.

Table I. The subset of best models $(\triangle \mathrm{AIC} \leqslant 2)$ of vegetation remnant (VR) occupancy by communal roosts of Black Vultures (Coragyps atratus) in the urban area of Manaus, Central Amazon, Brazil.

\begin{tabular}{llllcc}
\hline \multicolumn{1}{c}{ Model } & $\mathrm{AlC}_{\mathrm{c}}$ & $\Delta \mathrm{AlC}_{\mathrm{c}}$ & $\mathrm{w}_{\mathrm{i}}$ & $\mathrm{k}$ \\
\hline$\Psi$ & (Feeding), $\mathrm{p}()$. & 71.91 & 0 & 0.2195 & 3 \\
$\Psi$ & (Feeding+Thermal), $\mathrm{p}()$. & 72.89 & 0.98 & 0.1345 & 4 \\
$\Psi$ & (Feeding+Shape), $\mathrm{p}()$. & 73.20 & 1.29 & 0.1152 & 4 \\
$\Psi$ & (Feeding+Size), $\mathrm{p}()$. & 73.79 & 1.88 & 0.0858 & 4 \\
\hline
\end{tabular}

Models include different combinations of variables of VR occupation. "Feeding" denotes the distance of VRs to Feeding sites. "Thermal" denotes the distance of VRs to thermal power plants. "Shape" denotes the shape of VR. "Size" denotes the (AIC C ${ }_{C}$ ) Akaike Information Criterion corrected for small sample size; $(\triangle \mathrm{AlC})$ ) variation in Akaike Information Criterion values relative to the best model; $\left(w_{\text {. }}\right)$ Akaike weight, a normalized likelihood of the model; $\mathrm{K}$ is number of model parameters; $(\Psi)$ represent the occupancy probability; and $p$ represent the detection probability.

\section{DISCUSSION}

We found that among the variables investigated in this study, distance to feeding sites was the most important factor for roost site selection. In Manaus, the location of food sources for Black Vultures was already known (i.e., street markets, garbage dumps, open sewers) and Black Vultures used these feed- 
ing sites extensively. Black Vultures are able to adjust their home ranges, movement patterns, and flight behavior to local features (DeVault et al. 2004). Therefore, these birds may have adjusted to use the nearest possible roost to the food source to reduce the cost of movement.

Although the other variables could represent more safety (size), accessibility of roosts (shape), facilitated early-morning flight (proximity to thermal power plants), and potential ancillary roosts (proximity to other VRs), none of these variables were significantly correlated in our study. COLEMAN \& Fraser (1989) demonstrated that Black Vultures can roost communally in small to medium sized woodlots when roosts are near feeding sites. We observed Black Vultures roosting in very small VRs (i.e., $0.3 \mathrm{ha}$ ) in areas of intense human activity (i.e., street markets), but theses roosts were near large garbage containers used as feeders by vultures. It seems that Black Vultures adjust to small areas (theoretically less protected) when they find advantages in such areas, in this case, food supply. Closeness to thermal power plants had little influence on roost site selection. This is probably due to the fact that when the food location is known to Black Vultures, they approach the feeding site flapping rather than gliding (BuCKLEY 1997), demonstrating that they are not very dependence on thermals. Finally, the distances to other VRs varied little (from 0.01 to $1.39 \mathrm{~km}$ ) due o the large variability of these structures in Manaus, which may explain the lack of influence of this variable in our study.

When vulture communal roosts are located near human activity sites, vulture-human conflicts, including vulture-aircraft strikes, may arise (BALL 2009). For example, two of the three most abundant roosts that we identified (129 and 92 Black Vultures on average arriving within a 10 minutes period) were 1 and $0.7 \mathrm{~km}$ away from the Ponta Pelada Air Base. Normally, the strategies employed to minimize problems caused by vulture roosts include dispersing the birds by suspending vulture carcasses and the use of hand-held lasers and pyrotechnics in the roost (Avery et al. 2002, SeAmans 2004, Ball 2009). Although locally efficient, actions implemented only in one roost do not solve the vulture problem because birds repelled from a roost simply relocate to adjacent roosts and continue to operate in the area (Stolen \& Taylor 2003, Avery et al. 2006). For the efficient management of Black Vulture communal roosts, integrative measures are necessary.

The number and composition of individuals in a roost may be influenced by factors such as roost location, roosting site and abundance of birds in the roost (RABENOLD 1986, LAMBERTUCCI 2013). Therefore, the characterization of those sites regarding use and composition variations can provide tools to determine priorities for the management of the main roosts (i.e., more abundant and greater variation in age classes). However, as previously stated, roost dispersal does not reduce Black Vulture activity in an area. Our results suggest that effective management for preventing vulture-human conflicts include removal and proper disposal of food to reduce the attractive- ness of the site for vultures. A management plan to control the problems caused by Black Vulture communal roosts in urban areas should be based on significantly reducing their food supply through: improving the quality of garbage collection, installing and/or adjusting the sewage collection systems, replacing open garbage cans with closed garbage cans to prevent vulture access, and environmental education campaigns to reduce indiscriminate garbage disposal by local communities.

Additionally, we suggest caution before starting vulture management. A radical reduction in the availability of food does not necessarily mean that vultures will leave the area. These birds probably will feed on other resources, which can result in attacks to livestock, poultry, and domestic animals (Avery \& Cummings 2004). Competition for key resources with other bird species can also arise (CARRETE et al. 2010). It is important to consider translocation of birds to places were human-vulture interactions are not negative (HuMPHREY et al. 2000). On the other hand, it is important to consider that Black Vultures play an important role as cleaners in the environment. The drastic reduction of scavenger bird populations can have socio-economic, cultural, and biodiversity impacts (MARKANDYA et al. 2008).

Therefore, our results suggest that food location is the main factor considered by Black Vulture when communal roost sites are selected. As the establishment of large vulture communal roosts next to airports represent a serious risk to aircrafts, management measures to minimize this risk are necessary. Based on our results, we recommend the radical reduction of food availability, mainly human refuse, next to the airport as a first step. After the reduction of food resources, harassment measures should taken towards the communal roost.

\section{ACKNOWLEDGMENTS}

We thank Matheus Montefusco, Felipe Furtado, Elide Queiroz, Sendy Santos, and Simone Carneiro for their competent field assistance. Thanks are also due to Vivian Dutra for her help with formatting, Gonçalo Ferraz, and Fernando AbadFranch for their help with the statistical analysis and Kylie Patrick, Janisete Miller, and Carter Miller for English revision. Weber G. Novaes was the recipient of a fellowship from Coordenação de Aperfeiçoamento de Pessoal de Nível Superior (CAPES). We are very grateful to Programa Fauna nos Aeroportos Brasileiros for logistical support.

\section{LITERATURE CITED}

AVERY, M.L. 2004. Trends in North American vulture populations. Proceeding of the Vertebrate Pest Conference 21: 116-121. Avery, M.L. \& J.L. Cummings. 2004. Livestock depredations by black vultures and golden eagles. Sheep and Goat Research Journal 19: 58-63. 
Avery, M. L.; J.S. Humphrey; E.A. Tillman; K.O. Phares \& J.E. HATCHER. 2002. Dispersing vulture roosts on communication towers. Journal of Raptor Research 36 (1): 45-50.

Avery, M.L.; J.S. Humphrey; E.A. Tillman \& M.P. Milleson. 2006. Responses of Black Vultures to Roost Dispersal in Radford, Virginia. Proceeding of the Vertebrate Pest Conference 22: 239-243.

BALL, S.A. 2009. Suspending vulture effigies from roosts to reduce bird strikes. Human-Wildlife Conflicts 3 (2): 257259.

Beauchamp, G. 1999. The evolution of communal roosting in birds: origin and secondary losses. Behavioral Ecology 10 (6): 675-687. doi:10.1093/beheco/10.6.675.

BLACKWELL, B.F. \& S.E. WRIGHT. 2006. Collisions of Red-tailed Hawks (Buteo jamaicensis), Turkey Vultures (Cathartes aura), and Black Vultures (Coragyps atratus) with aircraft: implications for bird strike reduction. Journal of Raptor Research 40 (1): 76-80. doi: http://dx.doi.org/10.3356/0892-1016(2006)40[76: CORHBJ]2.0.CO;2.

BuCKLEY, N.J. 1996. Food finding and the influence of information, local enhancement, and communal roosting on foraging success of North American vultures. The Auk 113 (2): 473-488. doi: http://www.jstor.org/stable/4088913.

BuCKLEY, N.J. 1997. Experimental tests of the information-center hypothesis with black vultures (Coragyps atratus) and turkey vultures (Cathartes aura). Behavioral Ecology and Sociobiology 41 (4): 267-279. doi: 10.1007/s002650050388.

BuCKLEY, N.J. 1998. Interspecific competitionbetween vultures for preferred roost positions. Wilson Bulletin 110 (1): 122125. doi: http://www.jstor.org/stable/4163907.

Buckley, N.J. 1999. Black vulture (Coragyps atratus), p. 411. In: A. Poole \& F. Gill (Eds.). The birds of North America. Philadelphia, Cornel Lab of Ornithology, 411p.

Burnham, K.P. \& D.R. Anderson. 2002. Model selection and multimodel inference: a practical information-theoretic approach. New York, Springer-Verlag, 488p.

Carrete, M.; S.A. Lambertucci; K. Speziale; O. Ceballos; A. Travaini; M. Delibes; F. Hiraldo \& J.A. Donázar. 2010. Winners and losers in human-made habitats: interspecific competition outcomes in two Neotropical vultures. Animal Conservation 13 (4):390-398. doi: 10.1111/j.1469-1795.2010.00352.x.

CENIPA. 2012. Brazilian bird strike database. Centro de Investigação e Prevenção de Acidentes Aeronáuticos Available online at: http://www.cenipa.aer.mil.br/cenipa/sigra/ detalhar?op=NDg4Nw=\&acao=detalhe [Accessed: $21 / \mathrm{V} / 2012$ ].

Coleman, J.S. \& J.D. Fraser, 1989. Habitat use and home ranges of Black and Turkey Vultures. Journal of Wildlife Management 53 (3): 782-792.

Devault, T.L.; B.D. Reinhart; I.L. Brisbin \& O.E. Rhodes 2004. Home ranges of sympatric black and turkey vultures in South Carolina. The Condor 106: 706-711.

EISERER, L.A. 1984. Communal roosting in birds. Bird Behavior 5 (2): 61-80.
Evans, B.A. \& T.A. Sordahl. 2009. Factors influencing perch selection by communally roosting Turkey Vultures. Journal of Field Ornithology 80 (4): 364-372. doi: 10.1111/j.15579263.2009.00242.x.

Hatchwell, B.J.; S.P. Sharp; M. Simeoni \& A. Mcgowan. 2009. Factors influencing overnight loss of body mass in the communal roosts of a social bird. Functional Ecology 23 (2): 367-372. doi: 10.1111/j.1365-2435.2008.01511.x.

Hines, J.E. 2006. PRESENCE2. Software to estimate patch occupancy and related parameters. USGS-PWRC. Available online at: http://www.mbr-pwrc.usgs.gov/softwere/ presence.html [Accessed: 21/V/2012].

Humphrey, J.S.; M.L. Avery \& A.P. McGrane. 2000. Evaluating relocation as a vulture management tool in north Florida. Vertebrate Pest Conference 19: 49-53.

LAMBERTUCCI, S.A. 2013. Variability in size of groups in communal roosts: influence of age-class, abundance of individuals and roosting site. Emu 113: 122-127.

LAmbertucci, S.A.; N.L. Jácome \& A. Trejo. 2008. Use of communal roosts by Andean Condors in northwest Patagonia, Argentina. Journal of Field Ornithology 79 (2): 138-146. doi: 10.1111/j.1557-9263.2008.00155.x.

Lowney, M. 1999. Damage by black and turkey vultures in Virginia, 1990-1996. Wildlife Society Bulletin 27 (3): 715719. doi: http://www.jstor.org/stable/3784093.

MacKenzie, D.I. \& J.A. RoyLe. 2005. Designing occupancy studies: general advice and allocating survey effort. Journal of Applied Ecology 42 (6): 1105-1114. DOI:10.1111/J.13652664. 2005.01098.x.

MacKenzie, D.I.; J.D. Nichols; G.B. Lachman; S. Droege; J.A. Royle $\&$ C.A. Langtimm. 2002. Estimating site occupancy rates when detection probabilities are less than one. Ecology 83 (8): 2248-2255. doi: http://dx.doi.org/10.1890/0012-9658(2002) 083[2248:ESORWD]2.0.CO;2.

Mandel, J.T. \& K.L. Bildstein 2007. Turkey Vultures use anthropogenic thermals to extend their daily activity period. The Wilson Journal of Ornithology 119 (1): 102-105. doi:10.1676/05-128.1

Markandya, A.; T. TAYlor; A. Longo \& M. MurTy 2008. Counting the cost of vulture decline - An appraisal of the human health and other benefits of vultures in India. Ecological Economics 67: 194-204. doi:10.1016/j.ecolecon.2008.04.020

McVey, K.J.; P.D.B. Skrade \& T.A. Sordahl. 2008. Use of a communal roost by Turkey Vultures in northeastern Iowa. Journal of Field Ornithology 79 (2): 170-175. doi: 10.1111/ j.1557-9263.2008.00159.x.

Patton, D.R. 1975. A diversity index for quantifying habitat edge. Wildlife Society Bulletin 3 (4): 171-173. doi: http:// www.jstor.org/stable/3781151.

Rabenold, P. 1986. Family associations in communally roosting black vultures. The Auk 103 (1): 32-41. doi: http:// www.jstor.org/stable/4086961.

RABENOLD, P. 1987. Roost attendance and aggression in black 
vultures. The Auk 104 (4): 647-653. doi: http://www.jstor.org/ stable/4087276.

SEamans, T.W. 2004. Response of roosting turkey vultures to a vulture effigy. Ohio Journal of Science 104 (5): 136-138.

Sgrillo, R. 2012. GE-Path, Cocoa Research Center (CEPLAC/ CEPEC). Ilhéus, Bahia, Brasil. Available online at: http:// www.sgrillo.net/googleearth/gepath.htm [Accessed: 12/V/ 2012].

STOLEN, E.D. \& W.K. TAYLOR. 2003. Movements of black vultures between communal roosts in Florida. Wilson Bulletin 115 (3): 316-320. http://dx.doi.org/10.1676/03-049.

Thompson, W.L.; R.H. Yahner \& G.L. Storm. 1990. Winter use and habitat characteristics of vulture communal roosts. Journal of Wildlife Management 54 (1): 77-83. http:// www.jstor.org/stable/3808904.

USAF. 2009. Top 50 USAF wildlife strikes by cost. U.S. Air Force Sustainment Center. Available online at: http:// www.afsc.af.mil/shared/media/document/AFD-080130040.pdf [Acessed: 15/I/2012]

WARD, P. \& A. ZAHAVI. 1973. The importance of certain assemblages of birds as "information-centres" for food-finding. Ibis 115 (4): 517-534. doi: 10.1111/j.1474-919X.1973.tb01990.x.

Wright, A.; R. YAHNER \& G.L. StoRm. 1986. Roost-tree characteristics and abundance of wintering vultures at a communal roost in south central Pennsylvania. Journal of Raptor Research 20 (3/4): 102-107.

Appendix 1. Descriptive data of vegetation remnants (VR) Black Vulture (Coragyps atratus) occupation status as a communal roost, Manaus, Central Amazon, Brazil.

\begin{tabular}{ccccccl}
\hline VRs & Size & Shape & $\begin{array}{c}\text { Nearest } \\
\text { VR }\end{array}$ & $\begin{array}{c}\text { Feeding } \\
\text { sites }\end{array}$ & Thermal & \multicolumn{1}{c}{ Status } \\
\hline 1 & 20.49 & 2.4 & 0.12 & 3.21 & 0.80 & Occupied \\
2 & 152.62 & 3.4 & 0.07 & 3.59 & 2.53 & Occupied \\
3 & 190.67 & 1.4 & 0.02 & 4.14 & 5.46 & Not occupied \\
4 & 60.89 & 1.9 & 0.01 & 2.40 & 4.00 & Not occupied \\
5 & 7.72 & 1.6 & 0.07 & 2.48 & 3.43 & Not occupied \\
6 & 61.63 & 1.3 & 0.02 & 5.66 & 5.00 & Not occupied \\
7 & 0.94 & 2.0 & 0.46 & 3.87 & 3.22 & Not occupied \\
8 & 47.54 & 4.4 & 0.02 & 1.68 & 1.34 & Not occupied \\
9 & 10.22 & 3.0 & 0.03 & 0.86 & 0.52 & Occupied \\
10 & 20.9 & 1.8 & 0.01 & 3.59 & 0.95 & Not occupied \\
11 & 8.46 & 1.9 & 0.11 & 1.26 & 5.54 & Not occupied \\
12 & 59.01 & 2.0 & 0.08 & 0.01 & 3.95 & Occupied \\
13 & 40.45 & 1.8 & 0.03 & 1.86 & 2.84 & Occupied \\
14 & 2.20 & 1.8 & 0.02 & 1.01 & 2.54 & Not occupied \\
15 & 2.00 & 1.8 & 0.01 & 0.75 & 3.06 & Occupied \\
16 & 68.86 & 1.5 & 0.03 & 1.73 & 1.49 & Occupied \\
17 & 0.68 & 1.4 & 0.09 & 0 & 4.68 & Occupied \\
18 & 54.91 & 3.0 & 0.04 & 1.67 & 0.71 & Occupied \\
19 & 0.92 & 2.4 & 0.08 & 1.88 & 1.93 & Not occupied \\
20 & 2.03 & 1.2 & 0.09 & 1.88 & 3.04 & Occupied \\
& & & & & & Contines
\end{tabular}

Appendix 1. Continued.

\begin{tabular}{rrrrccl}
\hline VRs & \multicolumn{1}{c}{ Size } & Shape & $\begin{array}{c}\text { Nearest } \\
\text { VR }\end{array}$ & $\begin{array}{c}\text { Feeding } \\
\text { sites }\end{array}$ & Thermal & \multicolumn{1}{c}{ Status } \\
\hline 21 & 129.75 & 2.1 & 0.02 & 1.1 & 2.70 & Not occupied \\
22 & 0.31 & 2.2 & 0.58 & 0.08 & 2.17 & Occupied \\
23 & 0.27 & 1.5 & 0.56 & 0.55 & 1.45 & Not occupied \\
24 & 8.65 & 1.8 & 0.12 & 0.08 & 2.88 & Occupied \\
25 & 3.46 & 1.5 & 0.31 & 3.50 & 3.23 & Not occupied \\
26 & 1.50 & 1.9 & 0.13 & 2.87 & 3.09 & Not occupied \\
27 & 6.52 & 2.5 & 0.08 & 1.84 & 1.87 & Not occupied \\
28 & 0.65 & 1.6 & 0.08 & 1.56 & 2.22 & Not occupied \\
29 & 1.20 & 1.7 & 0.01 & 3.26 & 3.28 & Not occupied \\
30 & 1.98 & 1.8 & 1.39 & 0.41 & 4.00 & Occupied \\
31 & 2.06 & 1.1 & 0.14 & 2.31 & 1.25 & Not occupied \\
32 & 0.46 & 2.1 & 0.1 & 2.02 & 2.34 & Not occupied \\
33 & 773.89 & 2.5 & 0.02 & 0 & 2.11 & Occupied \\
34 & 10.82 & 2.0 & 0.27 & 3.22 & 0.77 & Occupied \\
35 & 359.57 & 2.0 & 0.01 & 2.86 & 3.10 & Not occupied \\
36 & 3.94 & 2.0 & 0.11 & 2.37 & 3.98 & Not occupied \\
37 & 1.41 & 1.4 & 0.29 & 0.22 & 3.02 & Not occupied \\
38 & 10.42 & 1.6 & 0.03 & 1.04 & 1.00 & Not occupied \\
39 & 11.11 & 2.0 & 0.03 & 0.17 & 3.10 & Occupied \\
40 & 32.02 & 1.7 & 0.01 & 1.28 & 1.69 & Occupied \\
\hline
\end{tabular}

Size in hectares. For details about shape see methods section. VR nearest is the distance of VRs to the nearest VR in $\mathrm{km}$. Feeding sites is the distance of VRs to Feeding sites in $\mathrm{km}$. Thermal is the distance of VRs in kilometers to thermal power plants.

Appendix 2. The complete set of 32 models of vegetation remnant (VR) occupancy by communal roosts of Black Vultures (Coragyps atratus) in the urban area, Manaus, Central Amazon, Brazil.

\begin{tabular}{lllll}
\hline \multicolumn{1}{c}{ Model } & $\mathrm{AlC}_{\mathrm{c}}$ & $\Delta \mathrm{AIC}_{\mathrm{c}}$ & $\mathrm{w}_{\mathrm{i}}$ & $\mathrm{k}$ \\
\hline$\Psi$ (Feeding), $\mathrm{p}()$. & 71.91 & 0 & 0.2195 & 3 \\
$\Psi$ (Feeding+Thermal), $\mathrm{p}()$. & 72.89 & 0.98 & 0.1345 & 4 \\
$\Psi$ (Feeding+Shape), $\mathrm{p}()$. & 73.20 & 1.29 & 0.1152 & 4 \\
$\Psi$ (Feeding+Size), $\mathrm{p}()$. & 73.79 & 1.88 & 0.0858 & 4 \\
$\Psi$ (Feeding+VR near), $\mathrm{p}()$. & 74.32 & 2.41 & 0.0658 & 4 \\
$\Psi$ (Feeding+Size+Thermal), $\mathrm{p}()$. & 74.85 & 2.94 & 0.0505 & 5 \\
$\Psi$ (Feeding+Shape+Thermal), $\mathrm{p}()$. & 74.99 & 3.08 & 0.0471 & 5 \\
$\Psi$ (Feeding+Thermal+VR near), p(.) & 75.33 & 3.42 & 0.0397 & 5 \\
$\Psi$ (Feeding+Size+Shape), p(.) & 75.48 & 3.57 & 0.0368 & 5 \\
$\Psi$ (Feeding+Shape+VR near), p(.) & 75.67 & 3.76 & 0.0335 & 5 \\
$\Psi$ (Feeding+Size+VR near), p(.) & 76.24 & 4.33 & 0.0252 & 5 \\
$\quad$ Null & 76.85 & 4.94 & 0.0186 & 2 \\
$\Psi$ (Feeding+Size+Thermal+VR near), p(.) & 77.30 & 5.39 & 0.0148 & 6 \\
$\Psi$ (Feeding+Size+Shape+Thermal), p(.) & 77.33 & 5.42 & 0.0146 & 6 \\
$\Psi$ (Feeding+Shape+Thermal+VR near), p(.) & 77.55 & 5.64 & 0.0131 & 6 \\
$\Psi$ (Thermal), p(.) & 77.72 & 5.81 & 0.0120 & 3 \\
$\Psi$ (Feeding+Size+Shape+VR near), p(.) & 78.02 & 6.11 & 0.0103 & 6 \\
$\Psi$ (Shape), p(.) & 78.10 & 6.19 & 0.0099 & 3 \\
$\Psi$ (Size), p(.) & 78.59 & 6.68 & 0.0078 & 3 \\
$\Psi$ (VR near), p(.) & 78.61 & 6.70 & 0.0077 & 3 \\
& & & Continues
\end{tabular}

ZOOLOGIA 30 (6): 607-614, December, 2013 
Appendix 2. Continued.

\begin{tabular}{|c|c|c|c|c|}
\hline Model & $\mathrm{AIC}_{\mathrm{c}}$ & $\Delta \mathrm{AIC}_{\mathrm{c}}$ & $w_{i}$ & $\mathrm{k}$ \\
\hline$\Psi$ (Thermal+VR near), $\mathrm{p}()$. & 79.39 & 7.48 & 0.0052 & 4 \\
\hline$\Psi \quad($ Size+Thermal), $\mathrm{p}()$. & 79.50 & 7.59 & 0.0049 & 4 \\
\hline$\Psi$ (Shape+VR near), $\mathrm{p}()$. & 79.78 & 7.87 & 0.0043 & 4 \\
\hline$\Psi$ (Shape+Thermal), $\mathrm{p}()$. & 79.80 & 7.89 & 0.0042 & 4 \\
\hline$\Psi$ (Feeding+Size+Shape+Thermal+VR), $\mathrm{p}()$. & 79.92 & 8.01 & 0.0040 & 7 \\
\hline$\Psi$ (Size+VR near), $\mathrm{p}()$. & 80.17 & 8.26 & 0.0035 & 4 \\
\hline$\Psi$ (Size+Shape), $\mathrm{p}()$. & 80.21 & 8.30 & 0.0035 & 4 \\
\hline$\Psi$ (Size+Thermal+VR near), $\mathrm{p}()$. & 80.95 & 9.04 & 0.0024 & 5 \\
\hline$\Psi$ (Shape+Thermal+VR near), $\mathrm{p}()$. & 81.52 & 9.61 & 0.0018 & 5 \\
\hline$\Psi$ (Size+Shape+VR near), $p()$. & 81.79 & 9.88 & 0.0016 & 5 \\
\hline$\Psi$ (Size+Shape+Thermal), $\mathrm{p}()$. & 81.91 & 10.00 & 0.0015 & 5 \\
\hline$\Psi$ (Size+Shape+Thermal+VR near), $\mathrm{p}()$. & 83.48 & 11.57 & 0.0007 & 6 \\
\hline \multicolumn{5}{|c|}{$\begin{array}{l}\text { Models include different combinations of variables of VR occupation. } \\
\text { (Feeding) Distance of VRs to Feeding sites. (Thermal) Distance of VRs to } \\
\text { thermal power plants. "VR near" denote de distance of VRs to the nearest } \\
\text { VR. (Shape) Shape of VR. (Size) Size of VR. (AIC) Akaike Information } \\
\text { Criterion corrected for small sample size; ( }\left(A \mathrm{AIC}^{c}\right) \text { Variation in Akaike } \\
\text { Information Criterion values relative to the best model; ( } \mathrm{w}_{\text {) }} \text { ) Akaike weight, } \\
\text { a normalized likelihood of the model; (K) number of model'parameters; }(\Psi) \\
\text { Occupancy probability; }(\mathrm{p}) \text { detection probability. }\end{array}$} \\
\hline
\end{tabular}

Submitted: 21.IV.2013; Accepted: 26.IX.2013.

Editorial responsibility: Diego Astúa de Moraes 